\title{
Detection of a novel RYR1 mutation in four malignant hyperthermia pedigrees
}

\author{
Katherine E.Keating, Kathleen A.Quane, Bernadette M.Manning, Mary Lehane', Edmund Hartung ${ }^{2}$, Kathrin Censier3, \\ Albert Urwyler ${ }^{3}$, Monika Klausnitzer ${ }^{4}$, Clemens R.Muller ${ }^{4}$, James J.A.Heffron and Tommie V.McCarthy * \\ Department of Biochemistry and 'Department of Anaesthesia, University College, Cork, Ireland, 2Institute for Anaesthesiology, Josef Schneider Str 2 , \\ D-97080 Wurzburg, Germany, ${ }^{3}$ Department of Anaesthesia and Research, University Hospital, $\mathrm{CH}-4031$ Basel, Switzerland and ${ }^{4}$ Department of \\ Human Genetics, University of Wurzburg Biozentrum, Am Hubland, D.97074 Wurzburg, Germany
}

Received June 20, 1994; Revised and Accepted July 29, 1994

\begin{abstract}
Malignant hyperthermia (MH) is a potentially fatal autosomal dominant disorder of skeletal muscle and is triggered in susceptible people by all commonly used inhalational anaesthetics and depolarizing muscle relaxants. To date, six mutations in the skeletal muscle ryanodine receptor gene (RYR1) have been identified in malignant hyperthermia susceptible (MHS) and central core disease (CCD) cases. Using SSCP analysis, we have screened the RYR1 gene in affected individuals for novel MHS mutations and have identified a $G$ to $A$ transition mutation which results in the replacement of a conserved Gly at position 2433 with an Arg. The Gly2433Arg mutation was present in four of 104 unrelated MHS individuals investigated and was not detected in a normal population sample. This mutation is adjacent to the previously identified Arg2434His mutation reported in a CCD/MH family and indicates that there may be a second region in the RYR1 gene where MHS/CCD mutations cluster.
\end{abstract}

\section{INTRODUCTION}

Malignant hyperthermia (MH) is an autosomal dominant disorder of skeletal muscle and is one of the main causes of death due to anaesthesia. In susceptible people, an MH episode can be triggered by all commonly used inhalational anaesthetics such as halothane and by depolarizing muscle relaxants such as succinylcholine. The clinical features of the myopathy are hyperthermia, accelerated muscle metabolism, contractures, metabolic acidosis and tachycardia (reviewed in 1).

Susceptibility to MH (MHS) is predicted by observing the magnitude of contractures induced in strips of muscle tissue in vitro by caffeine alone and halothane alone $(2,3)$. This test is called the in vitro contracture test (IVCT). Patients who exhibit a normal response are diagnosed as MH normal (MHN) while those with an abnormal response to both caffeine and halothane are diagnosed as MH susceptible (MHS). Patients exhibiting an abnormal response to caffeine alone or halothane alone are diagnosed as $\mathrm{MH}$ equivocal (MHE(c) and $\mathrm{MHE}(\mathrm{h})$ respectively) (3).

Molecular genetic studies have shown that the MHS locus maps to the RYR1 region of human chromosome $19 q$ in many cases $(4,5)$ and to date, six RYR 1 mutations have been reported in MHS and central core disease (CCD) pedigrees. $\mathrm{CCD}$ is a rare inherited myopathy closely associated with MHS $(6,7)$.

The first reported RYRI mutation resulted in an Arg to Cys substitution at position 614 and has been found in $3-5 \%$ of human $\mathrm{MH}$ families investigated (8). This mutation was also shown to be present in all cases of swine affected with MH (9). Recently, we reported a Gly to Arg substitution at position 341 which accounts for approximately $10 \%$ of MHS cases investigated (10) and an Arg163Cys mutation (11) which accounts for 2-3\% of MHS cases and a CCD case. The mutations Gly248Arg, Ile403Met and Arg2434His have also been reported in the RYRI gene in three independent MHS and/or CCD pedigrees and appear to be private mutations $(11-13)$.

Genetic heterogeneity has been reported in MH $(14,15)$ and a second MHS locus has been tentatively localized to the q11.2-q24 region of chromosome 17 in North American pedigrees (16). Recent linkage studies in European MHS pedigrees support the existence of genetic heterogeneity but have excluded the possibility of a second MHS locus mapping to $17 \mathrm{q} 11.2-\mathrm{q} 24(17,18)$.

In an effort to identify new mutations in the RYR1 gene causing MH we have undertaken the systematic screening of the 15.5 $\mathrm{kb}$ RYR 1 gene in unrelated MHS individuals for mutations. We describe here the identification of a novel Gly2433Arg mutation which we detected in four unrelated MHS pedigrees.

\section{RESULTS}

SSCP analysis of the RYR1 gene in MH

For mutation analysis, cDNA was synthesized from total RNA isolated from skeletal muscle biopsy samples from 21 unrelated MHS patients. The previously reported MHS mutations were not detected in these samples (data not shown). Screening for single nucleotide changes in polymerase chain reaction (PCR) amplified RYR1 segments from the MHS patients was performed using the single-stranded conformation polymorphism (SSCP) method (19). PCR primers were designed so that the $15.5 \mathrm{~kb}$ coding sequence of the RYRI gene (20) could be amplified in short (250-450 bp) overlapping segments. Aberrant SSCP patterns were detected in different areas of the RYRI gene in 21 MHS patients. The majority of the SSCPs detected in these segments reflected commonly occurring polymorphisms (12). However, of the SSCPs detected, an aberrant pattern was present in RYR I segment $6995-7393$ (Figure 1) in patient III-3 of pedigree A (Figure 2) and direct sequencing showed the presence of the single 


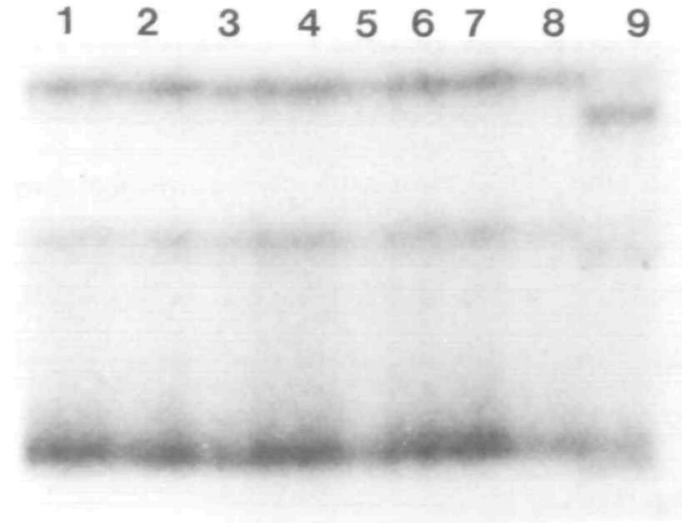

Figure 1. Autoradiograph of SSCPs detected in RYR1 segment 6995-7393 in normal controls (lanes 1, 2), and seven unrelated MHS individuals (lanes 3-9). Lane 9 is from individual III-3 of pedigree A. PCR was carried out with primers 6995 (5'-ACTTCCTGCGCTTTGCTGTCT-3') and 7393 (5'-GAGGCTGATGATGCCCACAAG-3') and at an annealing temperature of $57^{\circ} \mathrm{C}$ as previously described (11).

base substitution G7297A which results in the replacement of a Gly with an Arg at position 2433 (Figure 3). The complete RYRl gene in patient III-3 was investigated by SSCP analysis under three different electrophoretic conditions alongside control MHN samples and MHS samples known to bear the previously characterized Arg614Cys (21) or Gly341 Arg (10) mutations. In addition to the SSCP in segment $6995-7393$, SSCPs were detected in nine different segments of the RYRI gene from patient III-3. The nine SSCPs were considered innocuous polymorphisms as they were present in some of the control samples and/or were shown to be due to previously reported polymorphisms by restriction enzyme analysis (12).

As the G7297A mutation creates $A l w \mathrm{NI}$ and $D d e$ I restriction sites, either of these enzymes can be employed to check for the presence of the mutations in amplified RYR1 segments. In order to check for the presence of the G7297A missense mutation in the multi-exon RYRI gene (8) in genomic DNA samples, it was necessary to design PCR primers that would allow amplification of the mutated region from genomic DNA. Using the primers 7270 and 7301 (see Materials and Methods), it was possible to amplify a 55 bp genomic fragment encompassing the G7297A mutation. The amplified fragment was the same size as anticipated from the cDNA sequence and the presence of the mutation was verified by selective cleavage with the restriction enzyme $A l w \mathrm{NI}$ (Figure 4).

To establish whether the Gly2433Arg missense mutation was present in the normal population, 200 normal chromosomes were examined for the presence of the mutation. None displayed the candidate mutation. In order to determine whether this mutation was present in the RYRl gene of other MHS pedigrees and/or CCD pedigrees, 83 additional unrelated MHS and four unrelated CCD patients were investigated for the presence of the mutation. The mutation was detected in one Irish and two German MHS patients (individuals III-8, IV-1 and III- 1 of pedigrees B, C and $\mathrm{D}$, respectively).

Segregation analysis of the Gly2433Arg mutation was performed in the families of individuals displaying the mutation and showed that the mutation co-segregated with the MHS phenotype in each family with the exception of one individual, namely individual III-5 of pedigree A (Figure 2).
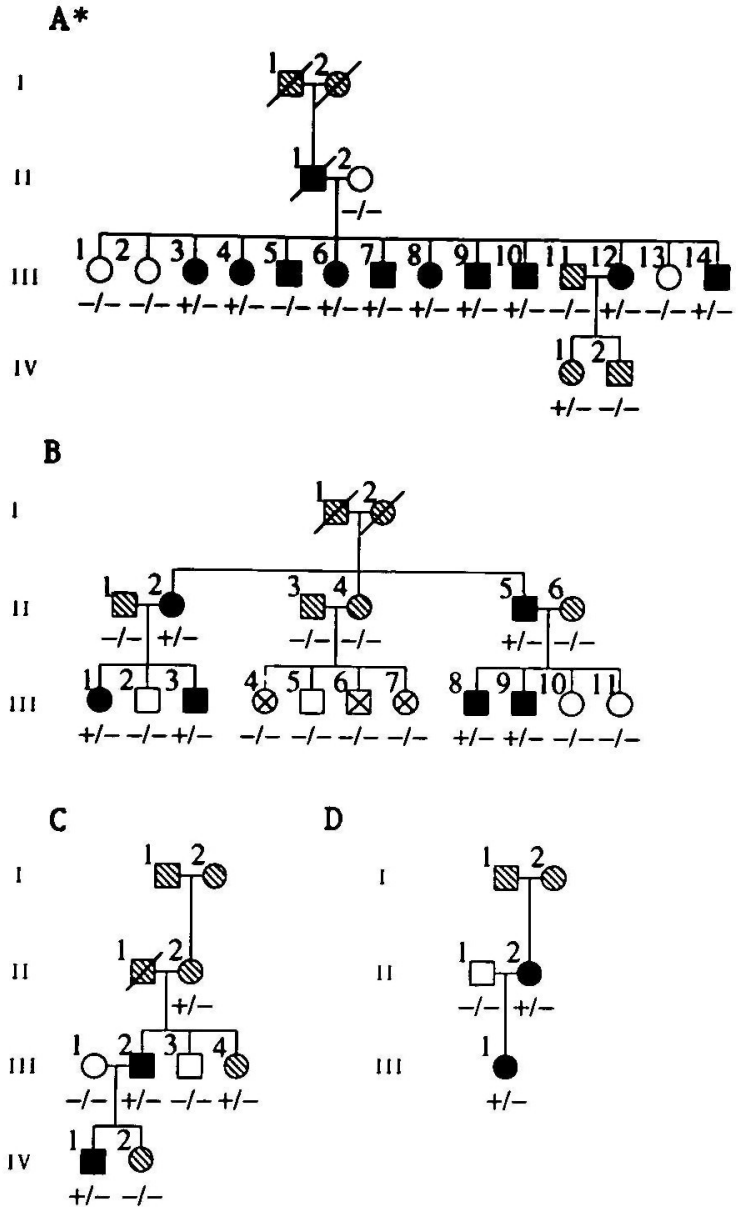

\begin{tabular}{ll}
$\square \bigcirc$ MHN & $\bigotimes \otimes$ MHE (h) $\otimes$ Untested \\
$\square$ \\
\hline MHS
\end{tabular}

Figure 2. Segregation of the RYR1 G7297A mutation in four MH pedigrees. + indicates the presence of the mutant allele, - indicates the presence of the normal allele. *Family A was tested by the caffeine contracture test prior to the introduction of the standardized European IVCT protocol (3) in 1984. Family B, C and D were tested by the standardized European IVCT protocol

\section{DISCUSSION}

In an effort to identify new mutations in the RYR1 gene causing MHS, we have investigated the RYRI gene in unrelated MHS patients for the presence of new mutations by the SSCP method and have detected a novel Gly2433Arg mutation in four of 104 unrelated Caucasian MHS patients. The Gly2433Arg mutation segregates with MHS in the pedigrees investigated with the exception of individual III-5 of pedigree A. The MHS diagnosis of the individuals in family A by the IVCT was performed in 1982, prior to the introduction of the standardized IVCT protocol (3). At this time, a patient was diagnosed as MHS if muscle biopsy strips produced a sustained increase of $0.2 \mathrm{~g}$ baseline tension at a caffeine concentration of $2 \mathrm{mM}$ or less. The result of the contracture test on individual III-5 was $0.64 \mathrm{~g}$ at $2 \mathrm{mM}$ caffeine and therefore, individual III-5 was diagnosed as MHS. Since the introduction of the standardized IVCT protocol, MHS diagnosis requires that the patient exhibits a positive response 


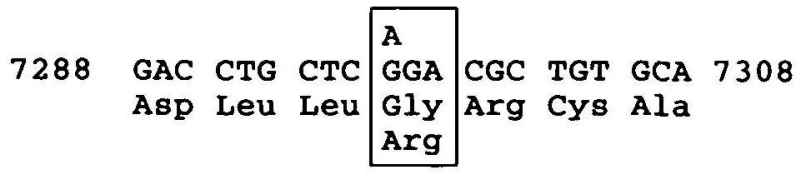

Figure 3. Nucleotide and deduced amino acid sequences of the region of the RYRI gene bearing the G7297A mutation. The alteration of the normal sequence CTCGGNNNCTG starting at nucleotide 7294 to the mutant sequence CTCAGNNNCTG creates an $A l w N I$ and a DdeI site in the mutant sequence.

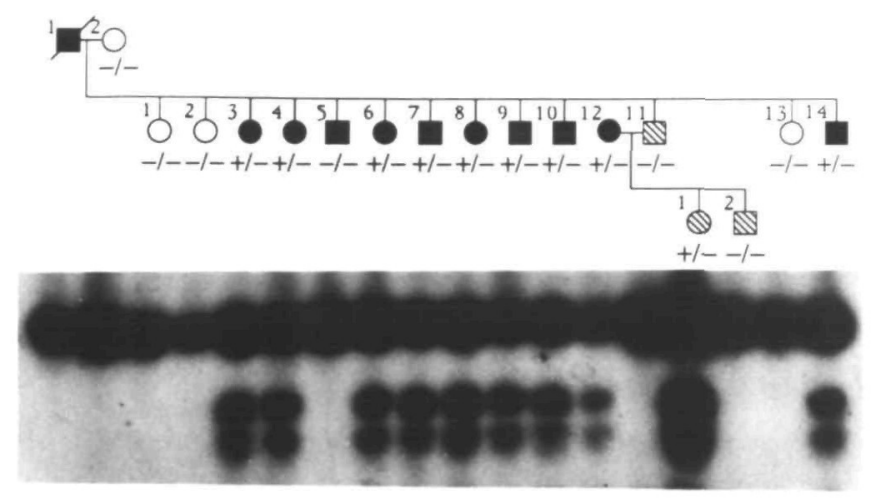

Figure 4. Segregation of the G7297A mutation by restriction enzyme analysis in members of pedigree A. Autoradiograph of the digestion products of the 55 bp PCR amplified segment encompassing the G7297A mutation with $A$ IwNI. Cleavage of the 55 bp mutant allele with $A l w N I$ results in 27 and 28 bp products.

to caffeine and halothane independently. The Gly2433Arg mutation segregates precisely with the MHS phenotype in the families diagnosed by the standard IVCT. Thus, the most likely explanation for the absence of the mutation in individual III-5 is that this individual has recorded a false positive reaction in the IVCT. In support of this notion, it has been reported that the North American IVCT protocol (which is largely similar to the European protocol) achieves a sensitivity of $100 \%$ in MHS detection. However, to achieve this sensitivity, the specificity of the test is compromised to $78 \%$ (22). Therefore, it is reasonable to assume that false positive diagnoses also exist using the European protocol especially before standardization in 1984. Furthermore, we have recently shown (10) that responses of up to $0.9 \mathrm{~g}$ tension occurred in Gly341Arg negative $\mathrm{MHE}(\mathrm{c})$ individuals within pedigrees in which the Gly34IArg mutation was segregating precisely with the MHS phenotype (10). It is possible that a second mutation causing MHS or contributing to an abnormal IVCT response is present in family A. However, the tight association between the Gly2433Arg mutation and the MHS phenotype in the pedigrees investigated and the absence of the mutation in 200 normal chromosomes tested argues strongly in favour of this mutation being causative of MHS. In addition, examination of the RYRI genes sequenced to date $(9,20)$ and related cardiac (RYR2) (23) and brain (RYR3) (24) genes indicates that Gly 2433 is a functionally important amino acid in the RYR proteins since it is conserved across species (Figure 5). To obtain conclusive proof that this is a causative mutation, it will be necessary to investigate the effect of the Gly2433Arg mutation on the RYR1 channel activity and/or determine its effects in an animal model system.

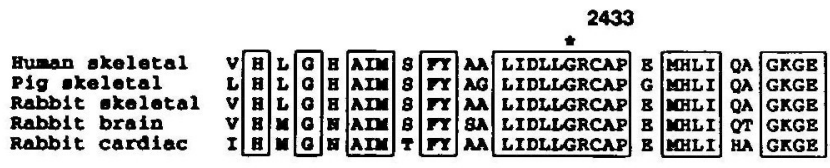

Figure 5. Amino acid sequence of the regions of the RYRI protein and related isoforms flanking the residue Gly2433. Residues identical to the human isoform are boxed.

Family B is unusual in that three of the four siblings were diagnosed as $\operatorname{MHE}(\mathrm{h})$. None of these individuals had the Gly2433Arg mutation. Examination of their contracture records shows that they all exhibited a marginal response to halothane which suggests that these patients may be normal from both a genetic and clinical viewpoint. However, since about $12 \%$ of probands are diagnosed as MHE in the IVCT (25) it is essential to classify all MHE individuals (including those in which an obvious MHS mutation is not segregating) as MHS until the relationship between the MHS and MHE phenotypes becomes much clearer.

The mutation reported here has diagnostic potential. However, as misdiagnosis could be fatal and as the reason for the apparent occurrence of the MHS false positive and MHE phenotypes is currently unclear, we strongly advocate corroboration of genetic diagnosis with the IVCT.

The detection of the Gly2433Arg mutation brings to seven the total number of RYR 1 mutations reported to date in MHS/CCD pedigrees. Five of the previously reported MHS/CCD mutations cluster in the amino terminal region of the RYR1 protein whereas the Gly2433Arg mutation is positioned adjacent to the previously identified Arg2434His CCD mutation. Interestingly, none of the patients with the Gly2433Arg mutation had clinical signs of CCD. Only family B has been investigated histologically and none of the MHS individuals in this family exibited central cores. This indicates that the Gly2433Arg mutation is associated with a milder phenotype than the Arg2434His mutation. The location of a second mutation close to the Arg2434His CCD mutation indicates that there may be a second region in the RYRI gene where MHS/CCD mutations cluster. The Gly2433Arg and the Arg2434His mutations occur in a domain of the RYR 1 protein thought to be modulated by ATP, phosphorylation and calmodulin binding (26). It will be interesting to determine if these mutations alter channel regulation with respect to these modulators.

\section{MATERIALS AND METHODS}

Genomic DNA was extracted from peripheral blood as described (27). Total RNA was extracted from $100 \mathrm{mg}$ muscle biopsy samples by guanidinium thiocyanate extraction (28). First strand cDNA synthesis and PCR amplification of RYRI gene segments was carried out using overlapping primers designed from the published human RYRI sequence (20), as previously described (10). Nondenaturing gel electrophoresis for SSCP detection and direct sequencing of PCR products was performed as previously described (10).

\section{Segregation studies}

A 55 bp fragment spanning the G7297A mutation of the RYRI gene was amplified from genomic DNA using PCR. The reactions were carried out in a total volume of $10 \mu \mathrm{l}$, with $100 \mathrm{ng}$ of genomic DNA, $20 \mathrm{ng}$ of each primer 7270 (5'-TTCTATGCCGCCTTGATCGACCTG-3') and 7301 (5'-TTAGATGCATCTCTGGTGCACAGC-3'), $0.2 \mathrm{mM}$ of each dNTP, $50 \mathrm{mM} \mathrm{KCl}, 10 \mathrm{mM}$ Tris-HCL, pH 9.0 at $25^{\circ} \mathrm{C}, 0.1 \%$ Triton $\mathrm{X}-100,1.5 \mathrm{mM} \mathrm{MgCl}$ and $0.5 \mathrm{U}$ of Taq polymerase (Promega) and $2 \mu \mathrm{Ci}$ of $\alpha^{32} \mathrm{P} \mathrm{dCTP}(3000 \mathrm{Ci} / \mathrm{mmol})$. A thermal profile of $94^{\circ} \mathrm{C}$ 
for $5 \mathrm{~min}$ followed by $94^{\circ} \mathrm{C}$ for $1 \mathrm{~min}, 51^{\circ} \mathrm{C}$ for $1 \mathrm{~min}$ and $72^{\circ} \mathrm{C}$ for $1 \mathrm{~min}$ for 30 cycles and then $72^{\circ} \mathrm{C}$ for $10 \mathrm{~min}$ was performed. A $1 \mu \mathrm{l}$ aliquot of the amplified 55 bp genomic fragment was then cleaved with $A l w N I$ in a reaction volume of $10 \mu \mathrm{l}$. The G7297A mutation results in the creation of the $A l w \mathrm{NI}$ site, producing 27 and 28 bp digestion fragments. Digestion products were resolved by electrophoresis through $20 \%$ polyacrylamide gels and visualized by autoradiography.

\section{Patients}

For the investigations reported here, muscle samples were obtained from 21 MHS patients and five MHN through the Cork, Basel and Wurzburg MH testing centres. The patients in pedigree A were tested for MH susceptibility prior to 1984 using an IVCT caffeine protocol similar to the standardized European Malignant Hyperthermia Group protocol (3) established in 1984. All other patients were investigated post-1984 using the standardized protocol. The probands in each pedigree are pedigree A: II-14; pedigree B: III-3; pedigree C: IV-1; and pedigree D: $\amalg-1$. Each proband suffered an MH episode during anaesthesia and recovered. Three individuals in pedigree B were diagnosed as MHE(h). The contracture data for the MHE patients were as follows: $0.35 \mathrm{~g}$ at $2 \%$ halothane for individual III-4; $0.2 \mathrm{~g}$ at $2 \%$ halothane for individual III-6; and $0.31 \mathrm{~g}$ at $2 \%$ halothane for individual $\amalg-7$.

\section{ACKNOWLEDGEMENTS}

This work was supported by grants from the Irish Health Research Board, the Wellcome Trust and the Deutsche Forschungsgemeinschaft (Mu 518/6-2).

\section{REFERENCES}

1. Britt, B.A. (1987) In Britt, B.A. (ed.), Malignant Hyperthermia. MartinusNijhoff Press, Amsterdam, pp. 325-367.

2. Rosenberg, H. and Reed, S. (1983) In vitro contracture tests for susceptibility to malignant hyperthermia. Anesth. Analgesia 62, 415-420.

3. European Malignant Hyperthermia Group (1984). Br. J. Anaesth. 56, $1267-1269$.

4. MacLennan, D.H., Duff, C., Zorzato, F., Fujii, J., Philips, M., Korneluk, R.G., Frodis, W., Britt, B.A. and Worton, R.G. (1990) The ryanodine receptor gene: a candidate gene for the predisposition to malignant hyperthermia. Nature 343, 559-561.

5. McCarthy, T.V. Healy, J.M., Heffron, J.J., Lehane, M., Deufel, T., Lehmann-Horn, F., Farrall, M. and Johnson, K. (1990) Localisation of the malignant hyperthermia susceptibility locus to human chromosome 19q12-13.2. Nature 343, 562-564.

6. Shy, G.M. and Magee, K.R. (1956) A new congenital non-progressive myopathy. Brain 79, 610-621.

7. Denborough, M.A., Dennett, X. and Anderson, R.M. (1973) Central core disease and malignant hyperthermia. Br. Med. J. 1, 272-276.

8. MacLennan, D.H. and Phillips, M.S. (1992) Malignant hyperthermia. Science 256, 789-794.

9. Fujii, J., Ostu, K., Zorzato, F., De Leon, S., Khanna, V.K., Weiler, J.E., O'Brien, P.J. and MacLennan, D.H. (1991). Identification of a mutation in porcine ryanodine receptor associated with malignant hyperthermia. Science 253, 448-451.

10. Quane, K.A., Keating, K.E., Manning, B.M., Healy, J.M.S., Monsieurs, K., Heffron, J.J.A., Lehane, M., Heytons, L., Krivosic-Horber, R., Adnet, P., Ellis, F.R., Monnier, N., Lunardi, J. and McCarthy, T.V. (1994) Detection of a novel common mutation in the ryanodine receptor gene in malignant hyperthermia: implication for diagnosis and heterogeneity studies. Hum. Mol. Genet. 3, 471-476.

11. Quane, K.A., Healy, J.M.S., Keating, K.E., Manning, B.M., Couch, F.J., Palmucei, L.M., Doriguzzi, C., Fagerlund, T.H., Berg, K., Ording, H., Bendixen, D., Mortier, W., Linz, U., Muller, C.R. and McCarthy, T.V. (1993) Nature Genet. 5, 51-55.

12. Gillard, E., Otsu, K., Fujii, J., Duff, C., De Leon, S., Khanna, V.K., Brin, B.A., Worton, R.G. and MacLennan, D.H. (1992) Polymorphisms and deduced amino acid substitutions in the coding sequence of the ryanodine receptor (RYR1) gene in individuals with malignant hyperthermia. Genomics $13,1247-1254$.

13. Zhang, Y., Chen, H.S., Khanna, V.K., De Leon, S., Philips, M., Schappen, K., Britt, B.A., Brownell, A.K.W. and MacLennan, D.H. (1993) A mutation in the human ryanodine receptor gene associated with central core disease. Nature Genet. 5, 46-49.

14. Levitt, R.C., Noouri, N., Jedlicka, A.E., McKusick, V.A., Marks, A.R., Shutack, J.G., Fletcher, J.E., Rosenberg, H. and Meyers, D.A. (1991)
Evidence for genetic heterogeneity in malignant hyperthermia susceptibility. Genomics 11, 543-547.

15. Deufel, T., Golla, A., Iles, D., Meindl, A., Meitinger, T., Schindelhauer, D., DeVries, A., Pongratz, D., MacLennan, D.H., Johnson, K.J. and Lehmann-Horn, F. (1992) Evidence for genetic heterogeneity of malignant hyperthermia susceptibility. Am. J. Hum. Genet. 50, 1153-1161.

16. Levitt, R.C., Olckers, A., Meyers, S., Fletcher, J.E., Rosenberg, H., Isaacs, H. and Meyers, D.A. (1992) Evidence for the localisation of a malignant hyperthermia susceptibility locus (MHS 2) to human chromosome 17q. Genomics 14, 562-566.

17. Iles, D.E., Segers, B., Sengers, C.A., Monsieurs, K., Halsall, P.J., Hopkins, P.M., Ellie, F.R., Hall-Curren, J.L., Stewart, A.D. and Wieringa, B. (1993) Genetic mapping of the $\beta_{1}$-and $\gamma$ - subunits of the human skeletal muscle L-type voltage- dependent calcium channel on chromosome $17 \mathrm{q}$ and exclusion as candidate genes for malignant hyperthermia susceptibility. Hum. Mol. Genet. 2, 863-868.

18. Sudbrak, R., Golla, A., Hogan, K., Powers, P., Gregg, R., Du Chesne, I., Lehmann-Horn, F. and Deufel, T. (1993) Exclusion of malignant hyperthermia susceptibility (MHS) from a putative MHS2 locus on chromosome $17 \mathrm{q}$ and of the $\alpha 1, \beta 1$, and $\gamma$ subunits of the dihydropyridine receptor calcium channel as candidates for the molecular defect. Hum. Mol. Genet. 2, 857-862.

19. Orita, M., Suzuki, Y., Sekiya, T. and Hayashi, K. (1989) Rapid and sensitive detection of point mutations and DNA polymorphisms using the polymerase chain reaction. Genomics 5, 874-879.

20. Zorzato, F., Fujii, J., Otsu, K., Philips, M., Green, N.M., Lai, F.A., Meissner, G. and MacLennan, D.H. (1990) Molecular cloning of cDNA encoding human and rabbit forms of the $\mathrm{Ca}^{2+}$ release channel (ryanodine receptor) of skeletal muscle sarcoplasmic reticulum. J. Biol. Chem. 265, $2244-2256$.

21. Gillard, E.F., Otsu, K., Fujii, J., Khanna, V.K., De Leon, S., Derdemezi, J., Britt, B.A., Duff, C.L., Worton, R.G. and MacLennan, D.H. (1991) A substitution of cysteine for arginine 614 in the ryanodine receptor is potentially causative of human malignant hyperthermia. Genomics 11, $751-755$.

22. Larach, M.G., Landis, J.R., Shirk, S.J. and Diaz, M. (1992) The North American Malignant Hyperthermia Registry: prediction of malignant hyperthermia susceptibility in humans: improving sensitivity to the caffeine halothane contracture test. Anaesthesiology 77, A1052.

23. Otsu, K., Willard, H., Khanna, V.K., Zorzato, F., Green, M. and MacLennan, D.H. (1990) Molecular cloning of cDNA encoding the $\mathrm{Ca}^{2+}$ release channel (ryanodine receptor) of rabbit cardiac muscle sarcoplasmic reticulum. J. Biol. Chem. 265, 13472-13483.

24. Hakamata, Y., Nakai, J., Takeshima, H. and Imoto, K. (1992) Primary structure and distribution of a novel ryanodine receptor/calcium release channel from rabbit brain. FEBS Letr. 312, 229-235.

25. Ording, H. (1987) In Brit, B.A. (ed.), Malignant Hyperthermia. MartinusNijhoff Press, Amsterdam, pp. 269-277.

26. Chen, S.R.W., Airey, J.A. and MacLennan, D.H. (1993) Positioning of major tryptic fragments in the $\mathrm{Ca}^{2+}$ release channel (ryanodine receptor) of rabbit skeletal muscle sarcoplasmic reticulum. J. Biol. Chem. 268, 22642-22649.

27. Old, J.M. and Higgs, D.R. (1983) In Weatherall, D. (ed. ) Methods in Haematology. Churchill-Livingstone, Edinburgh, p. 74.

28. Chomczynski, P. and Sacchi, N. (1987) Single step method of RNA isolation by acid guanidinium thiocyanate-phenol-chloroform extraction. Anal. Biochem. 162, 156-159. 